\title{
A Promising Connection of College Journalism Students and Community Engagement
}

\author{
Tse-Mei Chen ${ }^{1}$ \\ ${ }^{1}$ Department of Journalism, Shih-Hsin University, Taipei, Taiwan \\ Correspondence: Tse-Mei Chen, Department of Journalism, Shih-Hsin University, Taipei, Taiwan. Tel: \\ 886-2-236-8225 ext. 3142. E-mail: tchen@ mail.shu.edu.tw
}

Received: October 27, 2019

Accepted: November 26, 2019 Online Published: December 15, 2019

doi:10.5539/hes.v10n1p60

URL: https://doi.org/10.5539/hes.v10n1p60

\begin{abstract}
This study has explored the community engagement levels of Taiwanese college journalism students who took the community engagement and public journalism courses, as well as examined the way the practices have made an impact on them. The results indicated that taking community-oriented courses increases an interest in the community for the students. It enhances their abilities when participating in civic engagement activities more than their peers. The finding also showed through focusing the reportage on the residents and helping them to form a dialogue field for discussing community public issues, the participating students recognized the feeling that they have earned the trust and respect from the residents, and were able to rebuild their connection with society. Furthermore, the process not only improved the students' journalism skills so that they were more likely to produce in-depth and meaningful news coverage, but also strengthened their confidence to become a good news practitioner in the future.
\end{abstract}

Keywords: community/civic engagement; public journalism movement; college journalism students; media and society;

\section{Introduction}

The media environment in Taiwan is deteriorating (Taiwan News, 2014; Tong \& Lo, 2017). While dozens of media outlets provide round-the-clock news coverage, the provision of information and perspectives on public issues must be relatively adequate and efficient accordingly; however, because of the market oversaturation and profitability competition, news content has always been focused on trivial issues such as gossip, entertainment, or consumption news. The tabloidization tendency has not improved viewership ratings; however, it has led to severe criticism from the public toward the media outlets and journalists (Maxon, 2019; Taiwan News, 2014).

The "2019 Taiwan Public Credibility Survey" conducted by Taiwan's Global Monthly View showed that a "news reporter" obtained a trust rating of $27.5 \%$ and was the most distrusted profession by the Taiwanese people (Global Monthly View, 2019). In addition to the sporadic self-regulatory initiatives by the media and the supervisory efforts of the non-governmental organizations, however, in recent years, Taiwan's academia has reviewed higher education in journalism and has fine-tuned courses and teaching directions following the poor performance of the news media. Measures have been taken to build a healthy foundation for the future of the news media and society.

\subsection{Problem Statement: The Disconnect between News Media and Society}

While people can no longer read relevant news but rather superficial and self-benefiting content, as well as when the problems faced by society still remain unsolved, not only has it directly impacted people's willingness to watch the news, but also the participation in civic activities has gradually declined (Alotaibi, 2013; Clark \& Monserrate, 2011; Kaori, 2018). Such a trend is even more pronounced for the millennial generation born into a world of new technology. Studies have indicated that with the aid of technology, young people pay much more attention to private life or personal consumptions so that their involvement in public activities has been lower than that of the previous generation, which has led to people's indifference and alienation toward current affairs in the long run (Bakker \& de Vreese, 2011; Graybeal \& Sindik, 2012; Mesch \& Talmud, 2010).

The aforementioned concern was the backdrop to the emergence of the public journalism movement and its community-oriented practices in America at the end of the last century. It was a revolutionary media movement 
launched in the 1990s when American news media sensed the indifference of the public toward political activities and public affairs, and realized the correlation between this phenomenon and the public's increasingly low satisfaction with the news media. The movement advocates that the media should be actively involved in the community and care for various aspects of their living environment, culture, and industrial development, and further help solve problems faced by the community and its residents. Besides increasing the viewership of the news, the ultimate goal of the movement is to establish the decisive role of news media in a democratic society, and a long term relationship between the media and the public (Dzur, 2002; Merrit, 1995; Rosen, 1996; 1999).

Simultaneously, in the journalistic higher educational fields, journalism educators believe that traditional journalism has largely emphasized elite sources such as politics, celebrities, and scholars that relatively lack the opinions of the general public, which can also easily lead to the disconnection between the media and the public (Chen, 2017; Fink \& Schudson, 2013; Liang, 2016). Journalism educators suggest the practical orientation to promote civic involvement of the news media and to foster public participation in the community, which may enable the media workers to better manage complex and controversial issues (Clark \& Monserrate, 2011; Densmore, 2018). Also in Taiwan, the journalistic scholars have learned from the public journalism movement and started to promote community participation and civic engagement in journalism courses following the poor performance in Taiwan's news media and the weakening of public discourse, expectantly to train students to listen to public voices, encourage rational dialogue on public problems, and grow together with the community (Chang, 2015; Chen, 2017; Hu, 2014; Huang, 2017). The courses mostly contain keywords of course titles such as "community," "public," "civic," "engagement," "participation" and "action". This series of advocacy in Taiwan aims to build a healthy and positive relationship between the news media and the public. It further hopes to find new models for the journalism students to make the news media a solid foundation for a future democratic society.

\subsection{Research Purposes and Questions}

Numerous existing literatures reveal that the community engagement activities promoted in the school curriculums has been found to increase the students' civic knowledge, to impact their journalistic skills, and to fuel a desire to be engaged in local and community matters (Bernardo, et al., 2012; Bettencourt, 2015; Li, 2016; Schatteman, 2014); however, research on the specific operation and effectiveness of the community-based courses is lacking. Thus, the purpose of this present study is to examine the civic engagement levels of Taiwan's journalism students in higher education and the way civic engagement impacts their journalism practices. Through questionnaires and focus group interviews, this paper explores the way the students feel about community engagement activities of the news media after taking these type of courses, and if the students find a connection between community engagement practices and their work as young journalists. Research questions are as follows:

(1) What are the community engagement levels of the Taiwanese journalism students?

(2) How do the practices of community engagement and public journalism movements promoted by college journalistic courses impact on the journalism students?

\section{Literature Review: Youth, Community, and Civic Engagement}

Today, democratic countries have suffered from monopolized media problems, with the resources being held in the hands of a few conglomerates and political elites (Kishi, H., 2014; Sanders, 2017). While it is difficult for ordinary people to generate awareness or take action on public issues, journalism scholars believe that the traits and characteristics of a community may improve this problem due to its spatial geographic concentration and social structures (Fong, 2003; Rosen, 1996). Since a community as a social unit situated in a given geographical area, the residents often share with commonality such as religion, values, norms, history, local cultures, and identities. These characteristics of a community not only foster the residents' sense of belonging and social cohesion, but also enhance their willingness to solve problems that may arise, and to set and strive for common goals ( $\mathrm{Li}$, Chen \& Wang, 2006; Xu, Yen \& Tu, 2012). Moreover, in smaller areas where people have greater access to media channels, they are more likely to engage in, communicate about, or take actions pertaining to public issues in their communities (Fong, 2003). For this reason, the surging public journalism movement in America and Europe has used the community as the starting point for advocating civic participatory on public affairs in communities, as well as improving the relationship between the news media and the people.

Taiwan may seem to be a mature and democratic society, but the expressions of democracy have been overly simplified into the mere act of voting in elections, and have not deepened into the empowerment of local autonomy and civic engagement. Over time, this has led to the public only being enthusiastic about the elections and results, but in actuality, holding no interest in other social issues. Therefore, the essential task for moving 
Taiwan towards a more mature democratic society is to change their indifference toward social affairs, and to encourage them to engage actively in social issues as a pluralistic society ( $\mathrm{Li}, 2016$; Lin, 2013). The public journalism movement and its community engagement practices, which promotes mass media's active role in encouraging civic participation in communities may be a good start.

\subsection{Community Engagement Activity of The News Media}

When journalism academia saw that the news-reading population was in a significant decline, they believed this related to the trivial and superficial nature of the news content. That is, the news media do not prioritize news that cover the concerns of the public, leading to people being unable to gain valuable information, and thus, choosing to distance themselves (Rosen, 1996). Noticing the relationship between the public's indifference toward social issues and the decrease of news viewership would soon reflect on revenues, so many American news media outlets decided to play the role as the people's press in a meaningful sense of the term. During the 1990s, the American news media started to develop community spirit, which is a feeling of being positively engaged with one another in a community so that the residents are willing to care about where they live. With the power and resources, news media organizations believed they have the responsibility of increasing the public's understanding of the current social issues, thereby enlarging their capacity to actively participate in society (Dzur, 2002; Rosen, 1999; Voakes, 1999).

This series of journalism reform initiatives by the local news organizations are known as the public journalism movement. The core idea is to motivate the news media to proactively reach out to the communities and encourage the journalists to focus on public issues, so as to help the residents to discuss and solve the common problems they face. The movement also believed that the media should not address the public as consumers but as citizens; they should not only be the publisher of news and information, but also play an active role in civic engagement and drive society toward a better future (Rosen, 1996; Dzur, 2002).

Numerous literatures have shown that many news media outlets are in support of community-oriented practices emphasized by the public journalism movement (Voakes, 1999; Dickson, Brandon \& Topping, 2001; Rauch, Trager \& Kim, 2003). News workers expressed their willingness to play an active role in engaging the community and paying attention to the public's life; they also agreed that the news media should dedicate adequate resources to help the public communicate with each other toward common problems and to reach a consensus. The journalists believe that the news media's involvement in a community, and the provision of in-depth news coverage of daily life and public issues, not only helps a community to grow better, but also allows the news media to gain positive responses from the public, and finally increase the newspaper readership. With the news reform movement spreading to other places, a philosophy whereby the news media is obliged to be actively involved in the community is gradually gaining ground within modern societies (Rauch, Trager \& Kim, 2003).

Compared to the news media performance and social atmosphere in the 1990s in America, the current situation in Taiwan is even worse. Many more news media outlets have found that the infotainment channels are more popular than ordinary news channels. The trend not only causes people to be untrusting toward the news media, but also harms the development of a democratic society (Hu, 2014; Huang, 2017). Though mainstream media had occasionally focused on serious news with in-depth coverage, it usually has not continued due to the high cost incurred, not to mention the practicing of civic participatory of the news production or the community-oriented journalism (Chen, 2017; Hu, 2014).

Seeing the deterioration of the news environment, Taiwan's academic institutions, like universities, which relatively have abundant resources and advantages when compared to the market-oriented news media, have used community engagement practices of the public journalism movement as a blueprint, hoping to take advantages of its sources of higher education to cultivate the young journalists with a community spirit, and to foster their abilities of action-driven power to bring the community residents to care about where they live. This practice for journalism students not only helps them to reconnect with the real world, but also helps the community to become a better place to live, by focusing on their daily lives and public issues and showing them that the news media care, so as to improve the relationship between the media and the public.

Changes and adjustments can be seen in recent years in Taiwan, in that some of the journalism or communication departments of higher education, their media internship programs have been switched from practicing at news organizations to serving at closed area communities around the campus as community journalists. In other cases, media courses are planned for visits to communities where the students could participate in the community activities with the local residents, so as to learn to reconnect the media with their society (Chang, 2015; Chen, 2017; Hu, 2014; Kuang, 2015). 


\subsection{Civic Engagement among Young Generations}

Over the years, scholars have always been concerned about the negative impact that declining levels of civic engagement has had on the development of a democratic society, when they saw the disconnection between the youngsters and public affairs seemed aggravated (Kaori; 2018); however, advances in the communication technology in the past decades have, indeed, brought considerable changes and advantages to the form of news consumption and the definition and methods of civic engagement among young people (Mancini, 2013; Mesch \& Talmud, 2010; Nguyen, 2012). Researchers in the contemporary society are thus suggested to make efforts in finding appropriate ways to measure and evaluate the next generation of public participatory culture and news media landscapes (Bakker \& de Vreese, 2011; Wang, 2013).

Exercising the right to vote is essential in a democratic society; however, it is not the only form of civic involvement. The concept includes from participating in political activities to organized voluntary activities focused on problem solving and helping others along with the communication revolution (Gil de Zuniga, Eulalia \& Rojas, 2009). That is, civic involvement in modern society can take many forms. According to the definition published by the American Psychological Association (American Psychological Association [APA], 2012), civic engagement encompasses a range of activities such as electoral participation, interacting with non-government organizations, calling an elected official to provide feedback on social issues, meeting with community residents to discuss public issues within the community, volunteering at neighborhood associations, and even distributing communal meals in church kitchens. The activities, whether done individually or collectively, directly or indirectly, can be termed as civic engagement activities.

Indeed, the advancement of the Internet and the popularization of smartphones provide more diverse and convenient channels for young people to partake in civic engagement activities. They are accustomed to sharing news and events information, discussing public issues, and expressing their opinions with their peers on social networking platforms. Lauterer (2006) pointed out that young people did not perform any worse than the previous generations in terms of community awareness and participation in public affairs. A survey conducted by The Pew Center for Civic Journalism on 18-24 year old Americans revealed that millennials have seen little to no change in their engagement in public affairs, or have performed even better as compared to their parents' generation. The study showed that in addition to volunteering in their communities, one-third of the respondents had either in person, or through signing petitions and commenting online, participated in a boycott or discussion of public issues during the past year. This revealed that young people remain interested in public activities, but have changed their ways in which they engage with said public or political issues (Pew, 2010).

Research by Mesch and Talmud (2010) believed that as emerging communication technologies mature and production costs decrease, it will open up doors for youngsters to engage in public affairs with many smaller discussion platforms targeting specific topics being set up, which will enhance the participants' sense of community and a feeling of belonging to the country. A Taiwanese communication researcher has found that the more often younger people associate with their social media, the more they engage in social and political affairs, including the exchange of opinions on public issues online, or appearing in person for activities with peers such as protests, fund-raisings, and petition events (Wang, 2013).

Simultaneously, school educators have suggested the promotion of public service or civic involvement with a community to reduce the social alienation of young students caused by new technology, when considering the fact that their disconnection to the world will hinder the development of a democratic society. Thus, middle schools and higher education institutions caught up with this trend and have advocated actions such as community activity engagement, community service learning, or social movement participation in the school curriculum. Through these activities, youngsters nowadays are provided with many more opportunities to engage in public affairs then before (Bettencourt, 2015; Bernado, Butcher \& Howard, 2012; Graybeal \& Sindik, 2012; Sandaran, 2012; Schtterman, 2014).

\subsection{Community-oriented Practices in Journalism Education}

While the bad performance of the news media has caused the general public's distrust and belittlement toward news workers, some academic educators have questioned traditional journalism studies focusing too much on training students to be equipped with practical skills to provide market-oriented news content. Rosen (1999) indicated that the superficial description of topics and events, the standard writing format, and excessive reliance on political figures and elite sources in journalistic operating models, fundamentally weakened the students' insight, understanding, and reflection on news topics, and has failed to solve public problems effectively. Other scholars stated that the traditional journalism education is lacking in qualities, such as fraternity, democracy, and pluralism; therefore, journalistic studies should forsake traditional classroom learning and adopt a community 
service and civic engagement learning model to allow the students to personally connect with society and learn about different ethnic groups, cultures, and local industries (Corbett \& Kendall, 1998; Dickson, T., Brandon, W. \& Topping, E., 2001; Hu, 2014; McDevitt, 2000).

Rosen(1996) and Merritt(1995), two of the major figures promoting American public journalism movement, have mentioned that one of the keys to successfully improve the relationship between the news media and society lies within the attitude and practice of the media organizations. They believed that instead of only focusing on the opinions of the elite, political figures, or scholars, journalists should learn to be in favor of reporting on what concerns people even it is only their daily routine, and let ordinary people express their ideas and opinions. In the long run, not only will people change their attitudes toward the news media, but they will also gradually show their care and interest in public affairs again (Rosen, 1999; McDevitt, 2000).

With the idea to repair the relationship between the news media and the public spread over time, journalistic education institutions and schools in many places, including Taiwan, strategized a series of community engagement activities in the journalistic courses for future journalism students, hopefully to have a positive connection with society. This includes the integration of discussion on public issues into the civic education course, as well as the formation of groups by students to highlight their hometown resources and engage in community service. Scholars believed that the activities not only increased the students' civic literacy to engage with and care for their community, but will also regain trust from the public on the news media (Clark \& Monserrate, 2011; Cox, 2018; Densmore, 2018; Graybeal \& Sindik, 2012).

Results of the studies of Graybeal \& Sindik (2012) and Liang (2016) have shown that the collaboration between educational institutions and local communities breaks down traditional community geographical boundaries, brings together different stakeholders, establishes a diverse civic communication system, and greatly increases community vitality and prosperity. Civic engagement advocacy in the schools were also found to have instilled in young students a sense of community spirit, social identity, as well as other values, which further facilitated them to have a better understanding of what is happening in the neighbourhood and in the real world (Bernardo et al., 2012; Densmore, 2018; Gil de Zuniga, Eulalia \& Rojas, 2009). Moreover, the students who had participated in the school driven community activities were also showcased to have better content in their news reporting and possess better news writing capabilities as compared to their peers (Dickson, Brandon \& Topping, 2001; Graybeal \& Sindik, 2012; Fink \& Schudson, 2013). Similar results were found in Taiwan that the university journalism students felt that the activities of civic engagement and the community-oriented news reportages have allowed them to feel the friendliness of local residents, and believe that people had regained confidence in the news media (Chen, 2017; Huang, 2017; Hu, 2014).

\subsection{Summary of Literature Review}

Taiwan's news media not only suffers from weak public discourse, but also alienates the ordinary people from social affairs due to the excessive competitiveness in the media industry. Higher journalism education should certainly not abdicate its responsibility to reverse this trend of news media's over commercialization. Modeled after the public journalism movement, Taiwan's academia has launched a series of community engagement practices in the courses attempting to reconnect the news media to the public. This study thus explores the community engagement levels of the journalism students, as well as examines the way these practices impacts on them.

\section{Method and Research Design}

The present research is a case study that uses questionnaires and focus group interviews to explore the impact of community engagement activities and the public journalism movement in the journalistic courses on journalism-major students of a university in northern Taiwan. A Case study refers to an in-depth and systematic investigation of the cause and effect of problems of an individual, group, or a special event. Case studies are objective descriptions of facts and cannot be fabricated. The purpose of case studies is to give a thorough understanding of social facts, and to seek a solution to problems (Gary, 2011). This method of research allows the researcher to take a complex and broad phenomenon, and narrow it down into a manageable research questions. By collecting qualitative or quantitative datasets about a real-life event, the researcher gains a more in-depth insight into the phenomenon.

The public journalism movement and community-oriented practices has been carried out in areas such as Europe and America for a long time; however, it is still an emerging field in Taiwan. There is little known literature on this subject, let alone empirical data and research. This study is based on the concepts of the relevant research done in foreign countries but revised into a research framework that is consistent with the local situation in Taiwan. 


\subsection{Community Engagement Courses Description}

The research participants of this study are university students in the journalism department in one of Taiwan's universities in the north. Two required courses, "Community and Communication" in the first semester and "Public Journalism" in the second semester, being a total of four credits, are provided for sophomores with goals to provide students real-life experience to engage with the society and to build a positive relationship between the news media and the public in the long run.

"Community and Communication" course required students to form groups and selected a nearby community for onsite visits. Through one semester of observation, participation, and interaction with the community residents, students were to produce news reports on various aspects of the community but not limited to its cultures, history, lifestyle, individual profiles, local industries and its future development. In the class of "Public Journalism" in the second semester, returning to the same community they visited in the first semester, the students were to carry out the community-oriented practices in the vein of the public journalism movement. The class required students to be informed of public issues that are of concern to the community by interviews and surveys. Students were to collect comprehensive information and then produce news to heighten the visibility of these issues before inviting referred authorities to have face-to-face public meetings with the community. Residents were encouraged to participate the community meeting launched by the journalism students, who at the same time strived for facilitating the residents to talk, discuss, and generate rational dialogues in the meeting, helping them to reach a consensus in the end.

\subsubsection{Steps of Civic Engagement Movements}

The planning of the community engagement curriculum of the two classes is based on the public journalism movement ideals and practiced in local communities in Taiwan. The specific steps taken by the students are as follows:

(1) Take the initiative to immerse oneself into the community and actively listen to their voices: The news media should be an active role to enter the community for the long term and perform in-depth observation and immersion. They are to listen to the voices of the residents, understand the characteristics of the community, and learn about the living space of the community residents.

(2) Produce community-oriented news reportage to enhance a sense of community belongingness: The community news includes the people, history, culture, local industry, and other public issues, with the intention to strengthen the awareness of their living environment, and to provide a sense of belonging and cohesiveness among the residents.

(3) Discover community problems through surveys and provide relevant information and possible solutions: The news media is to use surveys or focus group talks to collate public concerns of community common problems, and to gather and transmit relevant information to the residents to better enhance their understanding of the issues and foster their abilities to discuss and think of possible solutions.

(4) Reflect on issues concretely and hold public community meetings: The news media is to use its organizational resources and expertise to reflect on issues relevant to local authorities, and invite said authorities, affiliated organizations, and community residents to have a face-to-face discussion to reach a consensus.

\subsection{Sources of Data}

\subsubsection{Questionnaires}

In order to understand the support level of the journalism students toward community engagement activities and the public journalism movement, the study made modification from four assessment concepts used in a survey conducted by Voakes (1999) on American journalists' support toward public journalism as follows:

(1) News media should focus on public issues that are relevant to the daily lives of the community residents.

(2) News media are to utilize ex-ante polls to understand community concerns.

(3) Journalists report not only news and information on the common issues faced by the community, but also provide possible solutions.

(4) News workers use resources of the media organization and are to facilitate residents to participate in community public discussions.

The questionnaires has a total of 15 questions, with the degree of support being expressed on a scale of one to five, with five being most supportive, and one being least supportive. A questionnaire was handed out to each of 
the students who completed taking two courses of "Community and Communication" in the first semester and "Public Journalism" in the second semester. A total of 64 questionnaires were issued, among which 12 were male, accounting for $18.75 \%$ of the total sample, and 52 were female, accounting for $81.25 \%$. The questionnaires were issued on June 11, 2016.

\subsubsection{Focus Group Interviews}

For the focus group interviews, this study focuses on the exploration of the attitudes and thoughts of journalism major students after they have completed the two community engagement courses. As for the questionnaire survey which was issued to each of the student of the class, the instructor invited volunteered students to participate in focus group interviews. Students are to share their views on the core meaning, design and planning, promotion methods and the substantial benefits of the classes. They are also to express their attitudes toward the news media in society, including the feeling of being connected to society, the power as being a journalist, the active role the news media plays in the community, and in the future development of a democratic society.

There were 41 course students that participated in the focus group interviews, among which 4 were male, and 37 were female. Interviews were held between September and December, 2016. A total of five focus group meetings were held, with about 6-8 students participating each time. The focus group is a research methodology in which a carefully planned series of discussion is designed to emphasize a series of topic discussions being conducted in a comfortable, inclusive, and non-threatening environment, to discover the trend and regularity of the research topic (Krueger \& Casey, 2000). The specially trained focus group interviewer personally led the participants to have open group discussions to better understand their real feelings and opinions on the research topic.

\section{Research Findings}

\subsection{Strong Support of Public Journalism Activities in Community}

The questionnaire results showed that most students were willing to support the four practices associated with community engagement activities. Among them, two mild practices including "place focus on common issues concerning the public" and "endeavor to provide news and information and all possible solutions" had the highest proportion of support, at $81.5 \%$ and $88 \%$ respectively. Meanwhile, about $60 \%$ of the participants supported the more proactive approaches including "news media units to hold meetings and advocate for residents' participation" and "news media to utilize ex-ante polls to decide on topics to cover" (Table 1).

Table 1. Journalism Students' Attitudes in Support of Public Journalism

\begin{tabular}{llll}
\hline $\begin{array}{l}\text { Supporting percentages (\%) } \\
\text { Concepts of public journalism movements }\end{array}$ & most supportive & supportive & total supportive \\
\cline { 1 - 1 } $\begin{array}{l}\text { to focus on public issues concerning } \\
\text { the public (Gentle) }\end{array}$ & $25.1 \%$ & $56.4 \%$ & $81.5 \%$ \\
\hline $\begin{array}{l}\text { to provide news and information and } \\
\text { possible solutions (Gentle) }\end{array}$ & $32.5 \%$ & $45.6 \%$ & $88.1 \%$ \\
$\begin{array}{l}\text { to organize public meeting for dialogues and } \\
\text { advocate residents' participation (Proactive) }\end{array}$ & $17.9 \%$ & $43.7 \%$ & $61.6 \%$ \\
\hline $\begin{array}{l}\text { use polls or focus groups to decide on } \\
\text { topics to cover (Proactive) }\end{array}$ & $18.2 \%$ & $44.2 \%$ & $62.4 \%$ \\
$\mathrm{n}=64$ & & &
\end{tabular}

Note. $\mathrm{n}=64$

The results revealed that most journalism students were willing to step out of the classroom and establish a certain degree of connection with the community and engage with the residents' public lives. The mild approaches of practicing community-oriented practices in communities, in fact, does not differ much from the traditional journalism ideals; both rather emphasize the journalists' primary responsibility to focus on public affairs that are of concern to the residents and provide them with information and possible solutions.

It was seen here that the percentage of Taiwanese journalism students who support the idea of a 'proactive attitude' of public journalism, including to organize a meeting for public discussion and using a survey to poll community's common problems of concern to the residents, was $20 \%$ less than that of the 'gentle attitude' approaches. This result revealed a more conservative attitude toward bold approaches on practicing public journalism for journalism students, who expressed their uncertainties when public journalism deviates too far from traditional ways of news reporting. They believed that it is not the journalists' responsibility, but rather the governmental officers, mayors, legislators, or lawmakers who should be holding an open dialogue with the 
public and making use of the polls to understand the problems and concerns of the public.

Overall, the questionnaire analysis found that the Taiwanese journalism students were open-minded toward public journalism and its community engagement practices. They not only support the news media workers to engage with community residents and to focus on their everyday lives, but are willing to initiate a dialogue field for the residents to discuss public issues of concerns, striving to make a better public life of them.

\subsection{Positive Impacts on College Journalism Students}

The results of focus-group interviews showed participation in the community engagement courses appears to positively impact the level of civic engagement for college journalism students. They showed their appreciation of the community involvement courses which greatly enhanced their confidence to be part of the news industry, and to be a better journalist in the future.

\subsubsection{Provide Chances of Understanding the Society}

The students were in favour of community engagement and the public journalism movement in the communities. They believed that by visiting local communities and placing their focus on the residents' daily life and the local cultures, customs, and history led by the department and the teachers, did provide them with the chances of better understanding a society.

When I was little I had the chance to attend a community activity once or twice; however, that did not interest me at all. This time because of the class, we went [to a community] to observe and discover stories. The experience was different. You heard about stories firsthand that gave you a better understanding of things instead of just reading about them from the news. The course is time consuming, but in the end it's well worth it.

Through the arranged community involvement activities as required by the school curriculum, future young journalists will have direct access to engage with society. Though not all students were motivated by the program, the respondents made it clear that whether or not they choose to work in the news field in the future, participating in civic engagement activities brought about positive benefits, such as helping them to understand the diverseness, as well as making them more aware of current situations in the real world. One participant stated:

When you are civically involved in the community, you start to have a sense of belonging. It's like your heart being opened in that you saw lots of things you would never notice before. It's a necessary training for young journalists like us.

\subsubsection{Tell Better Stories when Focusing on the Public' Everyday Life}

Similar to the public journalism movement and the community-oriented practices that have gained much popularity, participating students agreed that news practitioners should refocus their news coverage on the public and their everyday life, because "that is the closest place to the public."

I found most of my best stories are from going to the nursing home, community activity center, or to a senior group meal center. The community engagement experiences influenced me a lot. Now I feel like I can always write the best stories of communities.

Focus group respondents stated that community involvement activities can not only enhance journalism skills, but even more important, can impact the type of news stories written:

It is important for us to be involved (in communities). It can get you closer to the news. Instead of doing stories like which candidate is more likely to win, or like how bad the economy is, once you are engaged with it and listen to people there, you find everyone has a story. You can really write a story better when you know how the news firsthand.

\subsubsection{Experience Media Empowerment and Proud to be a Journalist}

As journalism students became more actively involved in the communities, they felt the residents' attitudes became friendlier and more supportive, which gave these future journalists a sense of accomplishment and the strength to be more enthusiastically devoted to the community. One participating group that was planning a discussion meeting for a possible renewal of a playground park in the community shared the experience of operating a public journalism task which gave them the feeling of media empowerment. They stated in the beginning there were not many responses, but it turns out there were many residents, far more than the students expected, that showed up at the community meeting. The residents had a lively discussion and a consensus was reached. One respondent said "that's a feeling of fulfilment." Another student echoed "it's the first time to say 
I'm proud to be a journalist":

We made newspaper reports of a renewal project (of the playground) and provided possible solutions collected from scholars, experts, officials, and legislators. Then we delivered the newspaper to every house and encouraged the residents to join the discussion meeting. It just seemed that no one cared about the issue. However, at the meeting, we were thrilled to see so many residents to join us. At that moment I felt everything was worth it. Using our resources and profession to help the community was such an amazing experience for me.

The statement above showed that the focused coverages enhanced the visibility of a community problem, and the public meeting which was designed to provide an open field for residents to freely express their ideas, and increased the residents' willingness to join the discussion. Focus group students believed the process of practicing a public journalism case in the community not only allowed them to feel the power of being a journalist, but also regained the trust from the public toward the mass media.

\subsubsection{Enhance the Level of Civic Engagement Participation}

The focus group students stated that the community engagement curriculum influenced them to start paying attention to public affairs and local issues. One participant stated she would have only shared news in the past, but after taking the classes she is more willing to express her opinions online and engage in discussions with netizens, and even voluntarily goes to event sites to do report and/or participate if the topics are of interest to her:

I never said anything about the news I shared, just transferred it or pressed "like", not to mention attending any social movements in person, not even community activities. The community engagement course did inspire me in some way. Like in our community there was a participatory budget meeting last month. It was a proposal talking about establishing a commute-bike station in our neighborhood, which is exactly what I need. I joined them and said my opinions in public. I know I have the right to speak, and also I am obligated to make my community better. The proposal was passed in the end and I'm very proud of being there.

Another participant student stated she believes she knows more about current social issues than her peers. She even expressed a certain degree of dissatisfaction with the social awareness of other students:

It's just a small election for electing chiefs of villages, but I couldn't believe people just voted without even bothering to know what are the candidates' political views or what will they do if elected. This is the place where we live, and I just think it's not right of being apathetic.

To a certain degree, the participating students were quite cognizant of the fact that the community involvement experience had led them to consciously pay attention to relevant information on public affairs. Their level of participating on such public issues and their peer discussions has also been enhanced.

\section{Conclusion}

This present study has attempted to examine the attitudes of college journalism students on the results and effects of the implementation of the civic involvement and public journalism practice curriculum in local communities promoted by Taiwan's journalism educators, recognizing the deteriorating performance of the news media has led to people's indifference of public affairs, and is also harmful to Taiwan's democratic society. The study showed that the practicing of the community-oriented curriculum greatly enhances the ability of journalism majors to be aware of public issues and to care where they live. It also strengthens the confidence of future news practitioners as they experienced media empowerment, and being proud of themselves in establishing the news media as a positive actor within society.

The community-oriented practices not only motivated the journalism students to care for the community with a positive attitude, but also extended their civic engagement experiences to the general public. That is, the course allows future news practitioners to identify themselves to be better informed about current social developments, and to start taking an interest in other issues in the public sphere, especially in what has happened in the community or society they belong to. After attending the courses, they are better able to use the news media expertise and resources to express their views, and enhance their level of civic participations in public issues not only to join discussions, but also to take actions on solving the problems they face.

Overall, as young future journalism majors step out of the classroom and are more deeply involved in the community, they are strengthened to become news practitioners equipped with professional, empathetic, and democratic qualities, as well as shouldering the media social responsibility of higher education organizations. The results of the study are consistent with the studies of American scholars and others which showed that the 
promotion of civic engagement practices reconnect a positive relationship between the news media and society, and have proved to be a promising direction of development for future media environment. The case study in Taiwan also provides preliminary but specific ideas for the adjustments to the current higher journalism education curriculums.

As Taiwan's news media environment is presently riddled with chaos and uncertainty, it is necessary for journalism educators to rethink how to strike a balance between the various media orientations and the role of the media -- between market interests and media social responsibility, between focusing on political elites' opinions and being concerned of the everyday life of the general public, between the standard news production and the narrative and in-depth news stories, between the professional theory learning and the practice of civic engagement -- in order to cultivate future news practitioners to be possessed with professionalism, mindful caring for society, insights into issues, and the ability to take action. Today in Taiwan where the news media are in serious competition for resources and profits, higher journalism educational institutes here have just started promoting the practice of community-oriented journalism. Although we have, as yet to see its flourishing scene, we are fortunate to already be moving forward on this path.

\section{References}

Alotaibi, N. N. (2013). An Analysis of the implications of the growing tabloidization of news coverage on democratic politics. E-European Scientific Journal, 9(14). Retrieved from https://eujournal.org/index.php/esj/article/view/1078

American Psychological Association (2012). Civic engagement. Retrieved from http://www.apa.org/education/undergrad/civic-engagement.aspx

Bakker, T. P., \& de Vreese, C. H. (2011). Good news for the future? Young people, Internet use, and political participation. Communication Research, 38(4), 451-470. https://doi.org/10.1177/0093650210381738

Bettencourt, M. (2015). Supporting student learning outcomes through service learning. Foreign Language Annals, 48(3), 473-490. https://doi.org/10.1111/flan.12147

Bernardo, M. A. C., Butcher J., \& Howard, P. (2012). An international comparison of community engagement in higher education. International Journal of Educational Development, 32(1), 187-192. https://doi.org/10.1016/j.ijedudev.2011.04.008

Chang, C. (2015). Cultivate talents: The on-going reform of news practical education in Taiwan. Journal of Communication Research and Practice, 5(2), 215-233. http://doi.org/10.6123/JCRP.2015.016

Chen, T. (2017). To listen and hug the society: Reforms of journalism major courses. Chinese Culture and Communication, 2, 265-283.

Clark, L. S., \& Monserrate, R. M. (2011). High school journalists and the making of young citizens. Journalism, 12(4), 417-432. https://doi.org/10.1177/1464884910388225

Corbett, J. B., \& Kendall, A. R. (1998). Evaluating service learning in the communication discipline. Journalism \& Mass Communication Educator, 53(4), 66-76. https://doi.org/10.1177/107769589805300406

Cox, J. B. (2018). Beyond objectivity: Examining the effects of incorporating civic into higher education journalism courses. International Journal on Service Learning and Community Engagement, 10(2), 22-29. Retrieved from https://discovery.indstate.edu/jcehe/index.php/joce/article/view/457/456

Densmore, B. (2018). How do we know engaging community matters? Retrieved from https://medium.com/journalismthatmatters/how-do-we-know-engaging-community-matters-d057329f1981

Dickson, T., Brandon, W., \& Topping, E. (2001). Editors, educators agree on outcomes but not goals. https://doi.org/10.1177/073953290102200405

Dzur, A. W. (2002). Public journalism and deliberative democracy. Polity, 34(3), 313-336. https://doi.org/10.1086/POLv34n3ms3235394

Fink, K., \& Schudson, M. (2013). The rise of contextual journalism, 1950s-2000s. Journalism, 3-20. https://doi.org/10.1177/1464884913479015

Fong, C. (2003). Book review: Public journalism and free socialism. Communication Research, 76, 187-190.

Gary, T. (2011). A typology for the case study in social science following a review of definition, discourse, and structure. Inquiry, 17 (6), 511-521. https://doi.org/10.1177/1077800411409884

Gil de Zuniga, H., Eulalia, P. \& Rojas, H. (2009). Weblogs, traditional sources, online and political participation: 
An assessment of how the internet is changing the political environment. New Media \& Society, 11(4), 553-574. https://doi.org/10.1177/1461444809102960

Global Views Monthly (2019, May, 23). The results of 2019 "Taiwan Public Credibility Survey" have been released. [online magazine]. Retrieved from https://gvsrc.cwgv.com.tw/articles/index/14810

Graybeal, G. \& Sindik, A. (2012). Journalism students and civic engagement: Is there still a connection?" Community Journalism, 1(1), 29-46. Retrieved from

$\mathrm{http} / /$ journal.community-journalism.com/journalism-students-and-civic-engagement-is-there-still-a-connec tion/

Hu, Y. (2014). Beyond campus: From college internship media to community media. Journal of Communication Research and Practice, 4(2), 55-92. https://doi.org/10.6123/JCRP.2014.011

Huang, L. (2017). A study on the teaching practice of incorporating community work courses into service learning. Taiwan Social Work, 18, 29-62.

Kaori H. (2018). Japan's media: Facing public indifference more than distrust. Retrieved from https://www.nippon.com/en/currents/d00398/japan\%E2\%80\%99s-media-facing-public-indifference-more-t han-distrust.html?pnum=2

Kishi, H. (2014) Media concentration: A crisis of democracy. Retrieved from https://www.mediareform.org.uk/media-ownership/media-concentration-crisis-democracy

Krueger, R. A., \& Casey, M. A. (2000). Focus groups: A practical guide for applied research. Thousand Oaks, CA: Sage Publications.

Kuang, C. (2013). Common wealth column: Media is retrograding from democracy. Retrieved from https://opinion.cw.com.tw/blog/profile/47/article/22

Lauterer, J. (2006). Community journalism: Relentlessly local. Chapel Hill, NC: University of North Carolina Press.

Liang, S. (2016). Community engagement is what universities should be for. Retrieved from https://www.timeshighereducation.com/blog/community-engagement-what-universities-should-be

Li, Y. (2016). Book review: Empowered participation by Archon Fung. Taiwan. Human Right Journal, 3, 177-181. Retrieved from http://www.taiwanhrj.org/contents/237

Lin, K. (2013). Inclusion in public deliberation: Proceduralism and civil society perspectives. Taiwan Democracy Quarterly, 10, 137-183. https://doi.org/10.6676/TS.2014.27.1

Mancini, P. (2013). Media fragmentation, party system, and democracy. The International Journal of Press/Politics, 18, 43-60. https://doi.org/10.1177/1940161212458200

Maxon, A. (2019, Aug. 26). Majority of Taiwanese believe media doing a poor job [online newspaper]. Retrieved from http://www.taipeitimes.com/News/taiwan/archives/2019/08/26/2003721153

McDevitt, M. (2000). Teaching civic journalism: Integrating theory and practice. Journalism and Mass Communication Educator, 55, 40-49. https://doi.org/10.1177/107769580005500205

Merritt, D. (1995). Public journalism and public life: Why telling the news is not enough. Hillsdale, NJ: Laurence Erlbaum

Mesch, G., \& Talmud, I. (2010). Internet connectivity, community participation, and place attachment: A longitudinal study. American Behavioural Scientist, 53(8), 1083-1094. https://doi.org/10.1177/0002764209356243

Nguyen, A. (2012). The effect of soft news on public attachment to the news: Is infotainment good for democracy? Journalism Studies, 13 (5-6), 706-717. https://dx.doi.org/10.1080/1461670X.2012.664318

Pew Research Center (2010). The millennials: Confident, connected, open to change. Retrieved from http://www.pewsocialtrends.org/2010/02/24/millennials-confident-connected-open-to-change/

Rauch, J., Trager, K.D. \& Kim, E. (2003). Clinging to tradition, welcoming civic solutions: A survey of college students' attitudes towards civic journalism. Journalism \& Mass Communication Educator, 175-186. https://doi.org/10.1177/107769580305800206

Rosen, J. (1996). Public journalism is a challenge to you. National Civic Review, 85, 3-7. https://doi.org/10.1002/ncr.4100850103 
Rosen, J. (1999). What are journalists for? New Haven, CT: Yale University Press.

Sandaran, S. C. (2012). Service learning: Transforming students, communities and universities. Social and Behavioural Sciences, 66, 380-390. https://doi.org/10.1016/j.sbspro.2012.11.281

Sanders, B. (2017). How corporate media threatens our democracy [online magazine]. Retrieved from http://inthesetimes.com/features/bernie-sanders-corporate-media-threatens-our-democracy.html

Schatteman, A. M. (2014). Academics meet action: Community engagement motivations, benefits and constraints. Journal of Community Engagement and Higher Education, 6(1), 17-30.

Staff writer (2014, Feb. 23). Foreign policy: Taiwan media are turning people into zombies [online newspaper]. Retrieved from https://www.taiwannews.com.tw/en/news/2420835

Tong, J. \& Lo, S. (2017). Uncertainty, tabloidization, and the loss of prestige: New media innovations and journalism cultures in two newspapers in mainland China and Taiwan, In J. Tong, \& S. Lo, (Eds.), Digital technology and journalism (pp. 91-111). London: Palgrave Macmillan. https://doi.org/10.1007/978-3-319-55026-8_5

Wang, T. (2013). Facebook election? The impact of social media on political participation in Taiwan's 2012 presidential elections. Soochow Journal of Political Science, 31(1), 1-52. Retrieved from http://www2.scu.edu.tw/politics/journal/doc/j311/1.pdf

Voakes, P. (1999). Civic duties: Newspaper journalists' views on public journalism. J\&MC Quarterly, 76(4), 756-774. https://doi.org/10.1177/107769909907600411

Xu, C., Yen, C., \&Tu. C. (2012). The practice and rethinking of community empowerment: a case study of Paiwan tribe in Pingtung in Taiwan. Taiwan Social Work, 18, 29-62.

https://doi.org/10.29755/JCWCS.201204.0002

\section{Copyrights}

Copyright for this article is retained by the author(s), with first publication rights granted to the journal.

This is an open-access article distributed under the terms and conditions of the Creative Commons Attribution license (http://creativecommons.org/licenses/by/4.0/). 